\title{
Safe Surgical Retrieval of Endothelialized Ventricular Septal Defect Closure Device
}

\author{
Guangqian Lin, ${ }^{1}$ Yueqiu Su, ${ }^{1}$ Yongjun Qian ${ }^{2}$
}

${ }^{1}$ Department of Anesthesiology, West China Hospital, Sichuan University, Chengdu, Sichuan, P.R. China; ${ }^{2}$ Department of Cardiovascular Surgery, West China Hospital, Sichuan University, Chengdu, Sichuan, P.R. China

\section{ABSTRACT}

Surgical retrieval of endothelialized ventricular septal defect closure devices is associated with significant morbidity. We herein present a technique for the safe removal of such devices (Shanghai Shape Memory Alloy, China) from the heart.

\section{INTRODUCTION}

Ventricular septal defects (VSDs) are one of the most common congenital abnormalities. Percutaneous and periventricular closure of VSDs has become increasingly common. Hemolysis is a major complication risk after VSD device closure [Egbe 2016; Pedra 2010]. The device often needs to be percutaneously retrieved if device embolization, heart block, new valvular regurgitation, or hemolysis occurs, especially if the event occurs some weeks after deployment. Endothelialized devices adhere to the ventricles, making removal difficult without damage to the valvar apparatus and conduction system. We present a safe technique for the surgical removal of VSD closure devices with adhesion to the ventricular wall.

A 2-year-old girl was admitted to our department with recurrent hemoglobinuria. One month prior to admission, the patient was diagnosed with perimembranous VSD (10 $\mathrm{mm}$, left to right shunt) (Shanghai Shape Memory Alloy, China) and received successful transcatheter closure of the VSD in another hospital, using a $12 \mathrm{~mm}$ perimembranous VSD device. Hemoglobin was $10.0 \mathrm{~g} / \mathrm{dL}$, liver function tests were deranged (bilirubin $38.6 \mu \mathrm{mol} / \mathrm{l}$; direct bilirubin 8.5 $\mu \mathrm{mol} / \mathrm{l}$; AST $91 \mathrm{U} / \mathrm{l}$; LDH $2033 \mathrm{U} / \mathrm{l})$, and there was urobilinogen in the urine. Viral tests, including CMV, EBV, Hepatitis $\mathrm{A}$ and $\mathrm{B}$, all were negative. A $2 \mathrm{D}$ echo showed a $2 \mathrm{~mm}$ left to right residual shunt of the VSD and gradient of $50 \mathrm{mmHg}$ across the VSD. Surgical retrieval of the VSD closure device and VSD patch repair were planned for the patient.

A standard median sternotomy was performed. For cardiopulmonary bypass with cardioplegic arrest, access can be via the right atrium if there are perimembranous defects or via the pulmonary artery trunk if doubly committed defects. After surgical removal of the endothelialized tissue from the

Received December 19, 2019; 2020; accepted April 18, 2020.

Correspondence: Qian Yongjun, Department of Cardiovascular Surgery, West China Hospital, Sichuan University, Guoxuexiang 37th, 610041 Chengdu, Sichuan, P.R. China; +862885422897 (e-mail: qianyongjun@scu.edu.cn).

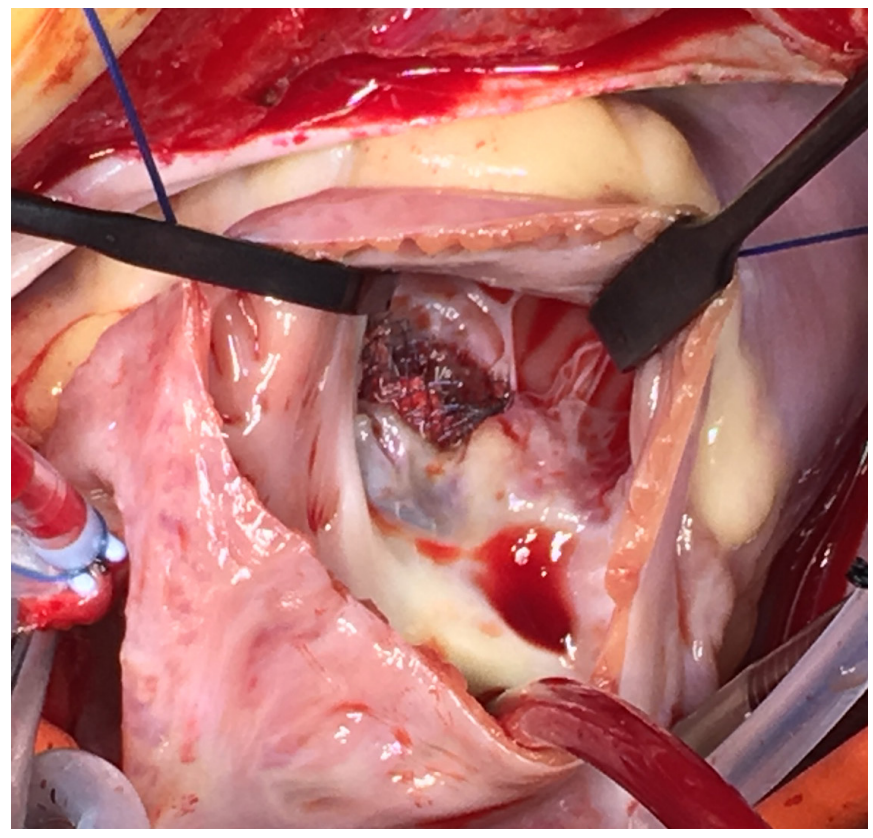

Figure 1. After surgical removal, the "knot" of the right ventricular disc and the fine wires spread out.
A

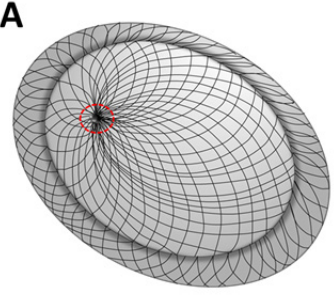

C

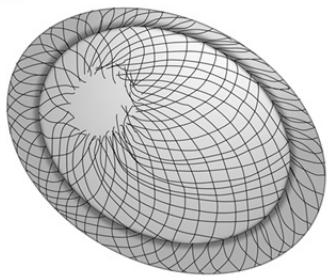

B

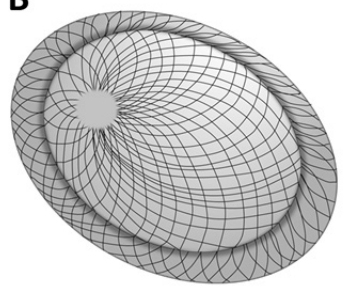

D

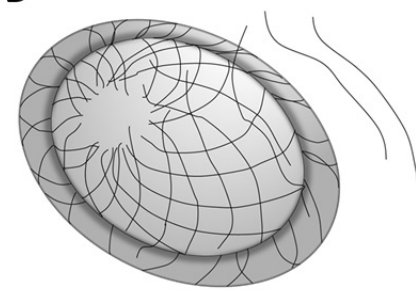

Figure 2. Safe retrieval of the endothelialized ventricular septal defect closure device from the ventricle after hemolysis. 
right ventricular disc (Shanghai Shape Memory Alloy, China), the "knot" was held up vertically and cut open with scissors; then the fine wires were spread out (Figure 1) and retrieved one by one with forceps. The left ventricular disc and polyester patches filling the discs and waist were easily removed when only two fine wires remained (Figure 2). The defect was then closed with a Gore-Tex/pericardial patch.

The patient successfully was discharged without further episodes of hemolysis. At the one-month follow up, the device position was found to be stable, there was a further significant decrease in residual leaks, and no more evidence of hemolysis was apparent.

\section{DISCUSSION}

Recently, improvements in device design and operator experience have resulted in the increasing adoption of percutaneous device closure in patients with VSD. However, complications, such as device embolization, heart block, new valvular regurgitation, and hemolysis, are being seen that require surgical intervention. Hemolysis induced by the prosthetic material used for occlusion is relatively infrequent and requires blood transfusion. Occasionally, surgical retrieval is unavoidable if lifelong blood transfusion will be required; however, endothelialization of the closure device makes the process more challenging [Martinez 2007].

Various techniques used for the surgical removal of closure devices have been reported, such as direct retrieval of the deployed device. Such devices are deployed from a sheath and, when being removed percutaneously, are resheathed for safe removal [Yates 2017]. However, the techniques only are applicable to retrieval interventions a few hours or days after deployment. Some weeks or months after deployment, the endothelialization of the appropriately positioned closure device makes direct retrieval impossible. Our technique minimizes aortic valve and conduction system complications. It is important that all cardiac surgeons involved in the care of patients with VSD closure devices are aware of this technique.

This technique provides a safe method for the surgical removal of positioned and endothelialized closure devices.

\section{REFERENCES}

Egbe AC, Poterucha JT, Rihal CS, Taggart NW, Cetta F, Cabalka AK, Pollak PM, Reeder GS, Hagler DJ. 2016. Transcatheter closure of postmyocardial infarction, iatrogenic, and postoperative ventricular septal defects: The Mayo Clinic experience. Catheter Cardiovasc Interv 86(7):1264-70.

Pedra CA, Pedra SR, Chaccur P, Jatene M, Costa RN, Hijazi ZM, Amin Z. 2010. Perventricular device closure of congenital muscular ventricular septal defects. Expert Rev Cardiovasc Ther 8(5):663-74.

Martinez MW, Mookadam M, Mookadam F. 2007. A case of hemolysis after percutaneous ventricular septal defect closure with a device. J Invasive Cardiol 19(7):E192-4.

Yates MT, Anderson DR. 2017. Safe Surgical Retrieval of Embolized Atrial Septal Defect Closure Device. 103(2):e213-e214. 